\title{
SUPPORT USERS TOWARDS MORE CONSCIOUS FOOD CONSUMPTION HABITS: A CASE STUDY
}

\author{
Bordegoni, Monica; \\ Carulli, Marina; \\ Spadoni, Elena
}

Politecnico di Milano

\begin{abstract}
Design for Sustainability is a research area based on a multidisciplinary approach, which has become increasingly important in recent years. Great attention is paid to the design of products that can impact on users' behaviours, through embedded smart technologies, e.g. Internet of Things (IoT). In fact, IoT systems are able to "dialogue" with the users, supporting the identification of any misbehaviour, and suggesting more sustainable ones.

This paper presents a research aiming at supporting users towards more conscious food consumption in their daily life to reduce food waste. As a case study, it has been developed an interactive system in which chicken eggs are used as main communication element. Indeed, the environmental footprint of the egg industry is very heavy, and eggs are one of the main wasted food. The interactive system consists of a physical product, an eggs tray, integrating sensors and actuators for handling the interaction with users. It is accompanied by an interactive application for monitoring eggs consumption, displaying eggs waste statistics, and an Augmented Reality part for children, aimed to improve their awareness about food waste and the impact on their food habits through an "edutainment" approach.
\end{abstract}

Keywords: Sustainability, Industrial design, Virtual reality

\author{
Contact: \\ Carulli, Marina \\ Politecnico di Milano \\ Mechanical Engineering \\ Italy \\ marina.carulli@polimi.it
}

Cite this article: Bordegoni, M., Carulli, M., Spadoni, E. (2021) 'Support Users Towards More Conscious Food Consumption Habits: A Case Study', in Proceedings of the International Conference on Engineering Design (ICED21), Gothenburg, Sweden, 16-20 August 2021. DOI:10.1017/pds.2021.541 


\section{INTRODUCTION}

Design for Sustainability is a research area based on a multidisciplinary approach, which has become increasingly important in recent years. The main goal of this approach is to design and develop more eco-sustainable solutions, services and products as regards their production, reuse and recycling processes. Furthermore, great attention is paid to the design of products, systems and services that can impact and modify users' behaviours, in line with the so-called "Design for sustainable behaviour" approach (Tand and Bhamra, 2008, Ceschin and Gaziulusoy, 2016).

For this purpose, several design experiences based on the use of advanced technologies, e.g. Internet of Things (IoT), have been proposed and experimented. In fact, through the use of embedded smart technologies, IoT systems are able to "dialogue" with the users, supporting them in the identification and understanding of any misbehaviour, and suggesting more sustainable ones.

The "food waste" phenomenon is one of the several erroneous behaviours related to environmental sustainability and to users' daily activities. According to the FAO (Food and Agriculture Organization of the United Nations), about one third of the food produced each year is lost during production and distribution or thrown away by consumers. Specifically, in Europe, the amount of food wasted by consumers is noticeably higher than the food loss during the production and distribution phases.

The effects of this phenomenon consist of waste of resources like water, land, energy, labour and money, and also production of gas emissions, contributing to the global warming and climate change. Organizations and countries have implemented instruments to face this problem. Examples are the awareness campaigns, such as the "International Day of Awareness of Food Loss and Waste" (http://www.fao.org/international-day-awareness-food-loss-waste/en/), and the SAVE FOOD project (https://www.save-food.org/). In spite of these and many other attempts, the amount of consumer food waste is constantly increasing.

This paper presents an experimental research aiming at supporting users towards more conscious food consumption in their daily life, in order to reduce food waste. As a case study, it has been developed an interactive system in which chicken eggs are used as main communication element. The case study has been selected for two reasons; first because the environmental footprint of the egg industry is very heavy, and also because eggs are one of the main wasted food. The interactive system consists of a physical product, an eggs tray, integrating sensors and actuators for handling the interaction with users. It is accompanied by an interactive application for monitoring eggs consumption, displaying eggs usage and waste statistics.

It has been proved that interactivity is a valuable and effective means in learning, for both adults and children. It grounds on sensory-motor experiences instead of a mere observation or listening, to improve our learning process according to the psychological theory of "embodied cognition" (Pecher and Zwaan, 2005). Also, it allows the users to catch the deep meaning of the subject-to-be-learnt and to elaborate a personal and critic vision. Therefore, interactivity is particularly appropriate to generate high and deep awareness about the "food waste" problem.

Besides, it is worth reporting that interactivity can be particularly effective in fostering durable behavioural changes, especially when the designed system is able to monitor the users' behaviours and to suggest nudge new actions and new habits. In fact, these features constitute the foundations for inducing behavioural changes in daily life (Prochaska and DiClemente, 1983). State of the art technology can provide a huge boost to this process, enabling the users to interact with several kinds of digital contents in an integrated, and stimulating experience.

The paper presents the literature review in the reference research areas, describes the objectives of the research, and the design, architecture, key features and development of the system, named EGGup.

\section{STATE OF THE ART}

Design for sustainability is part of the "sustainable development" (Bhamra and Lofthouse, 2007), which has been defined in 1987 as "development that meets the needs of the present without compromising the ability of future generations to meet their own needs" (World Commission on Environment and Development, 1987). Among the several strategies and approaches used to meet this important topic, the design discipline has been engaged with different aspects of sustainability subject and practice (Ceschin and Gaziulusoy, 2016). More specifically, according to Ceschin and Gaziulusoy (2016), several approaches to Design for Sustainability have emerged in the past decades. Among 
them, they highlighted the "Design for sustainable behaviour" (DfSB) approach, which is based on the fact that the users' behaviours produce important environmental impacts (Tand and Bhamra, 2008).

On this basis, several design experiences to influence users' behaviours have been performed (e.g. Wever et al., 2008; Montazeri et al., 2015, Graziosi et al., 2015, Scurati et al., 2020), accompanied by definitions of design approaches and guidelines. Among them, Bhamra et al. (2011) developed the DfSB model, that proposes a set of "design intervention strategies" which can be applied within design to inform, empower, provide feedback, and reward (with incentives and penalties) users. Moreover, other design strategies rely on "automatic" interventions, such as design solutions combined with advanced technology to persuade or control users' behaviours.

In line with these design strategies, IoT technologies can be used in the design of interactive systems, products and applications to allow a "dialogue" with the users, and to support them in the identification and understanding of any erroneous behaviour, and to suggest more sustainable ones. In those cases, the design of the user-system interaction represents one important aspect to take into account in the overall design process. Indeed, a well-designed interaction can be particularly effective for two reasons. First, it engages the users' body, an aspect that is considered fundamental for improving our understanding and learning process according to the well-known psychological theory of embodied cognition. This theory suggests that cognition is heavily grounded on sensory-motor experiences, meaning that better learning is achieved when the body is involved in the process, as compared to when the experience consists in a mere observation or listening (Pecher and Zwaan, 2005). Second, being actively engaged in the interactive process, instead of being the passive recipients of inputs and notions, allows the users to catch the deep meaning of the subject-to-be-learnt, to develop logical and semantic links with related topics, and to elaborate a personal and critic vision. State of the art technology can provide a huge boost to this process, enabling the users to interact with several kinds of digital contents in an integrated, and stimulating experience. Furthermore, the possibility to use interactive technologies to monitor the users' behaviour and push them to start new actions can be particularly effective in fostering durable behavioural changes and generate new habits. For all these reasons, interactive applications and systems are becoming more and more appreciated and effective, involving people through different senses and calling them to action. In the context of this research area, several applications and smart objects have been developed with the aim of making people think about the impact of humans on Earth. For instance, the "After Ice" (https://secondverse.org/ \#/after-ice/) mobile application uses Augmented Reality to simulate the effects of climate change around the world. The app simulates your location in various future scenarios of global ice melt and sea level rise. Also, on the basis of the "Human Footprint" exhibition (https://www.wikitude.com/ wikitude-eovision-bring-augmented-reality-frankfurt-book-fair/), the EoVision company developed a book named "OneEarth", in which a collection of 119 satellite images was presented and used to visualize with an Augmented Reality application the status of the Earth's environment. Similarly, NASA created different applications based on pictures from NASA's satellites and missions. Among them, a virtual gallery named "Images of Change" (https://climate.nasa.gov/images-of-change) features images of different locations on planet Earth, showing changes over time periods.

Among the several misbehaviours related to environmental sustainability and to users' daily activities there is the "food waste" phenomenon. In an analysis carried out in 2011 by FAO, annual global food waste is estimated to be about 1.3 billion tons, equivalent to about a third of the total food production intended for human consumption. According to the USDA (Buzby et al., 2014), in the United States a total of $31 \%$ of the food intended for human consumption is wasted each year, primarily in the home and in restaurants, and in Europe the food waste phenomenon is comparable. If we focus on food waste at home in developed countries (Wahlen and Winkel, 2016), the phenomenon is primarily related to the over-buying of food, often induced by supermarkets' special offers, to the preparation of over-generous portions of food (at home and also in restaurants), to fresh food not being preserved appropriately and, more in general, to the low cost of food compared to disposable income. Food waste phenomenon has negative impacts at the environmental and economic levels, and also raises serious questions from a social point of view. Wasting food is related to wasting of water, land, energy, labour and money, and also to the production of gas emissions, the contribution to global warming and climate change.

Many organizations and countries in the world have implemented different strategies and tools to face this problem. In 2015, the European Union created a list of Sustainable Development Goals, including the goal of halving per capita the consumers' food waste by 2030 . 
Food waste awareness campaigns, such as the "International Day of Awareness of Food Loss and Waste" (http://www.fao.org/international-day-awareness-food-loss-waste/en/) have been launched. Also, some organizations (for profit and non-profit) provide food aid by collecting food that would otherwise be thrown away and distribute it to poor people. Moreover, other initiatives are aimed at the reduction, recuperation and recycling of food products that can no longer be sold but are still edible.

However, in spite of all these attempts, the amount of consumers' food waste is constantly increasing, and one of the most wasted food are chicken eggs. The main reasons are the poor value attributed to chicken eggs, the fact that it is often cheaper to buy eggs in large package, also if users don't need such a big quantity, and that users don't pay attention the expiration date. Despite this poor perceived value, eggs production involves a big consumption of water (200 litres for each egg), and also involves a waste of resources like land, energy, farmers' work and money, and gas emissions, contributing to global warming and climate change.

\section{CASE STUDY}

On the basis of the literature review, the authors identified the opportunity to develop a solution, made of a physical product and an interactive application, to generate awareness about the impact of food waste on the environment, and make people reason about how they can directly contribute to limit the expansion of this problem. With the aim of increasing the awareness about "food waste" issue to people and, more importantly, to children, the authors designed and developed an interactive system named "EGGup". Even if different types of food products could be selected as key element of the system, chicken eggs have been chosen as main communication element. Chicken egg has been selected because is one of the main wasted food, and because it has a very important symbolic meaning, and is used in several cultures as symbol of life, of birth and regeneration, and of wholeness. EGGup is based on smart technology and aims at influencing people's behaviour with respect to eggs waste. The system has been designed according to the layers of design proposed by Selvefors et al. (2016). Table 1 presents the layers. First, we have identified the enabled activity and the type of artifact performing this activity. Then, we have defined the three functions of the product: operating, interactive and communicative. The operating function defines what the user should be able to do with the system. The interactive function defines the user's possibilities for digitally or physically interacting with the system. Eventually, the communicative function refers to the modalities with which the system communicates information to the users.

The design solutions proposed for the three functions aim at informing the user about the eggs expiration date and induce him/her to consume the eggs before they expire.

Table 1. Example of layers of design for the EGGup system.

\begin{tabular}{|l|l|}
\hline Layers of design & Design solutions \\
\hline Enabled activity & Monitor eggs expiring date and avoid waste \\
\hline Artifact type & Smart tray containing eggs \\
\hline Operating function & Check expiring date and inform users \\
\hline Interactive function & Insert expiring date. Monitor eggs status through the App. \\
\hline Communicative function & LEDs on smart tray. Graphical elements in the App. \\
\hline
\end{tabular}

The EGGup system has also been designed according to the "design intervention strategies" proposed by Bhamra et al. (2011). In particular, Table 2 presents the used "design intervention strategies" and the corresponding design solutions used in the EGGup system.

Table 2. Design intervention strategies and design solutions of the EGGup system.

\begin{tabular}{|l|l|l|}
\hline $\begin{array}{l}\text { Design intervention } \\
\text { strategies }\end{array}$ & Aims & Design solutions \\
\hline Eco-Information & $\begin{array}{l}\text { To make consumables } \\
\text { visible and } \\
\text { understandable. }\end{array}$ & $\begin{array}{l}\text { The EGGup Parent's application gives } \\
\text { information about the quantity of eggs in the } \\
\text { fridge and their quality, and statistics about } \\
\text { eggs' consumption and waste. }\end{array}$ \\
\hline Eco-feedback & $\begin{array}{l}\text { To inform users about } \\
\text { what they are doing and }\end{array}$ & $\begin{array}{l}\text { Smart Egg Tray and the Parent's application. In } \\
\text { both cases, the eggs status is associated with a }\end{array}$ \\
\hline
\end{tabular}




\begin{tabular}{|l|l|l|}
\hline & $\begin{array}{l}\text { to facilitate consumers to } \\
\text { make environmentally } \\
\text { responsible decisions. }\end{array}$ & $\begin{array}{l}\text { colour, and the user can understand which egg } \\
\text { is edible, or close to the expiration date or } \\
\text { already expired. }\end{array}$ \\
\hline Eco-spur & $\begin{array}{l}\text { To inspire users to } \\
\text { explore more sustainable } \\
\text { usage through providing } \\
\text { rewordings to good } \\
\text { behaviour. }\end{array}$ & $\begin{array}{l}\text { In the Children's application, an Augmented } \\
\text { Reality educational game is used to make } \\
\text { children learn more about food wasting and } \\
\text { give them positive feedbacks and points. }\end{array}$ \\
\hline $\begin{array}{l}\text { Eco-technical } \\
\text { intervention }\end{array}$ & $\begin{array}{l}\text { To persuade or control } \\
\text { user behaviour by design } \\
\text { combined with advanced } \\
\text { technology. }\end{array}$ & $\begin{array}{l}\text { Technologies embedded in the Smart Egg Tray } \\
\text { and the EGGup applications are interconnected } \\
\text { to support users in improving their food waste } \\
\text { habits and increasing the awareness about } \\
\text { "food waste" issue in children. }\end{array}$ \\
\hline
\end{tabular}

EGGup consists of an eggs tray, integrating sensors and actuators, which is linked to an interactive application for monitoring eggs consumption, and for communicating eggs usage and waste statistics. The Smart Egg Tray has a flat shape and is designed to be placed in the middle shelf of the fridge. The tray includes a set of egg holes, each having touch sensors and LED lights in order to enhance the value of the eggs and give immediate feedback and information about the egg expiration date and quality. The tray is also equipped with a Bluetooth module to connect and send information to the EGGup application.

The EGGup application consists of two modules. The first one has been designed for adults / parents of children. It is the main application and manages and controls the whole system: it is connected to the Smart Egg Tray and to the children's application. From this application the users can check remotely the quantity of eggs in the fridge and their quality, and also check statistics about the eggs' consumption and waste. The application also allows parents to verify the children's progresses.

The second module has been designed for children, who are aimed to improve their awareness about food waste and the impact on their food habits through an "edutainment" approach, which combines entertainment and educational contents. The entertainment part consists of an Augmented Reality Easter Egg search. When the Easter Egg is found, educational contents about the food waste problem in form of videos with fairy tales and legends can be enjoyed.

The Interaction Map of the EGGup system, showing the interaction flow, is shown in Figure 1.

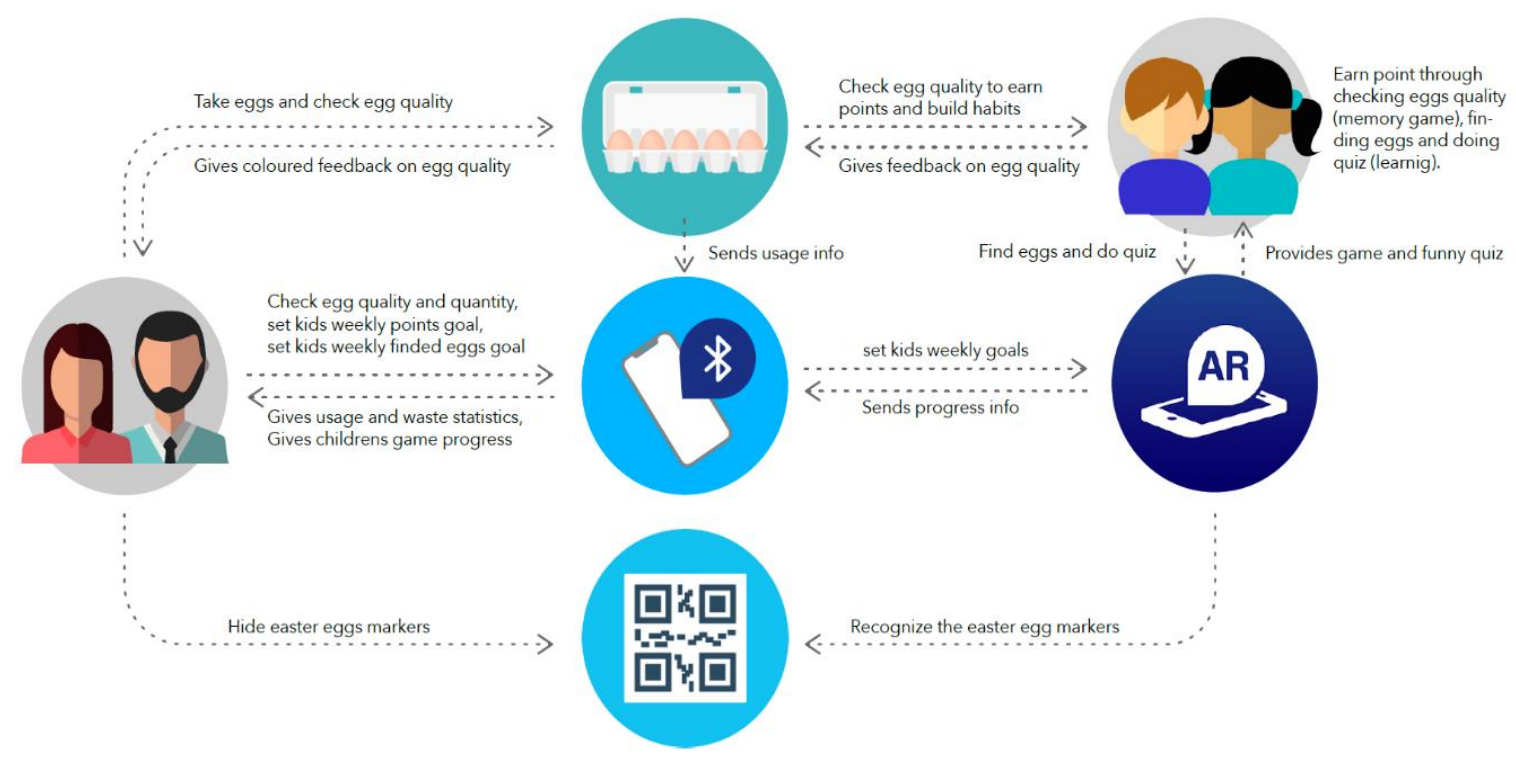

Figure 1. The interaction map of the EGGup system

The design process has been carried out keeping into account the final aim of the system that, according to the DfSB approach, is to influence users' behaviours and support users in adopting a more environmental-friendly attitude. Thus, the creation of a scenario that takes in consideration the sustainable life cycle of the product has not been considered as the focus of the project. Nonetheless, 
the hardware Smart Tray sustainability analysis could be particularly critical. Indeed, its environmental impact can be high especially regarding the disposal phase of the IoT components. In this vision, to reduce the product impact, the Smart Tray has been designed to be used for several years and to be easily disassembled into its components before its disposal.

\section{DESCRIPTION OF THE SYSTEM}

The architecture of the EGGup system is structured in three main components: a Smart Egg Tray, a Parent's application and a Children's application.

The first component of the interactive system consists in a Smart Egg Tray. This physical element presents precise spots on the tray surface that allow the storage of the eggs. Every egg is placed on a specific spot that features also a touch sensor and a LED light, to give immediate information about the egg presence, expiration date and quality thanks to a coloured feedback. Nonetheless the user can directly place the egg carton on the Smart Tray, some accessories has been designed to allow a high customisation of the User Experience. Moreover, a Bluetooth module allows the connection to the smartphone applications to send information about the egg presence on the Tray and about their lifetime. The Smart Tray external case has been developed by using 3D printed PLA, that combined with the LED lights gives a modern and hi-tech look to the product (see Figure 2).

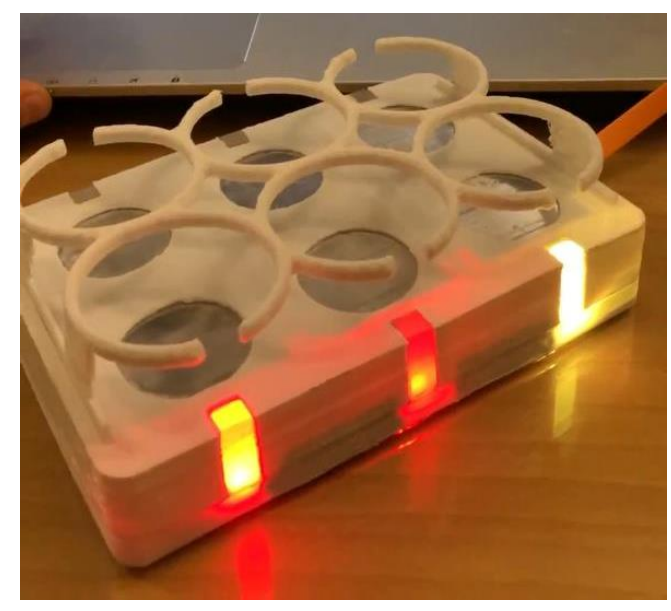

Figure 2. The Smart Egg Tray prototype

The second and the third components of the system consist of two smartphone applications designed for parents and children respectively. This Parent's application is directly connected to the Smart Egg Tray and also to the Children's application, as previously shown in Figure 1, and manages and controls the whole system. By using this application, the parent can be aware about the exact amount of eggs present in the fridge, with no need to directly check them. This feature is really helpful when the user is not at home, especially during the shopping time. Moreover, the application gives information about the quality of each egg, pointing out precisely each egg expiration date. On this basis it is possible to plan the eggs consumption, increasing awareness and preventing food waste. The application gives also information about usage and waste statistics. Furthermore, thanks to a direct connection with the Children's application it allows the parents to set weekly goals for their children and to displays also their educational game progresses. In this way, the Children's application usage is controlled by the parents according to the family need, and represents a powerful tool yet not requiring a mandatory stressful continuous usage. For what concerns the Children's application, it provides an "edutainment" system that combines educational content with entertainment. Practically, parents hide the eggs markers throughout the house and children have to search and find them. Whenever the children find a marker, an Augmented Reality egg appears, they receive a positive feedback and points and can take part to a funny quiz game. The quiz questions are created to make children learn more about food consumption, food conservation and food wasting. A timer makes the game more interesting and challenging. Also, the Children's application offers many other contents concerning sustainability, such as videos about food waste presenting stories in form of fairy tales and legends. Unity3D (https://unity.com/) and Vuforia (https://developer.vuforia.com/) software tools have been used to develop the two applications. Specifically concerning the Augmented Reality part, the virtual 
representations of the Easter Eggs have been developed in Unity3D, and the Vuforia software has been used for the development of the AR visualization of the contents.

\subsection{Smart Egg Tray}

The Smart Egg Tray dimensions and characteristics have been designed starting by analysing the shape of the chicken eggs. At first, the eggs can be classified in extra-large, large and small, and the average dimensions are $40-42 \mathrm{~mm}$ by $53-59 \mathrm{~mm}$. From this initial analysis the dimension of each egg spot diameter has been set at $45 \mathrm{~mm}$. For what concerns the dimension of the eggs cartons, it is independent from the eggs size, and is $305 \mathrm{~mm}$ by $105 \mathrm{~mm}$. On this basis it has been designed a flat tray on which it is possible to directly place every kind of eggs carton.

The external case is made by 3D printed Polylactic Acid (PLA), which is a polymer made from renewable resources with many suitable characteristics for this product. Particularly it does not release toxic fumes when oxygenated and can be safely used for any food packaging. The Smart Egg Tray also includes some components, as shown in Figure 3.

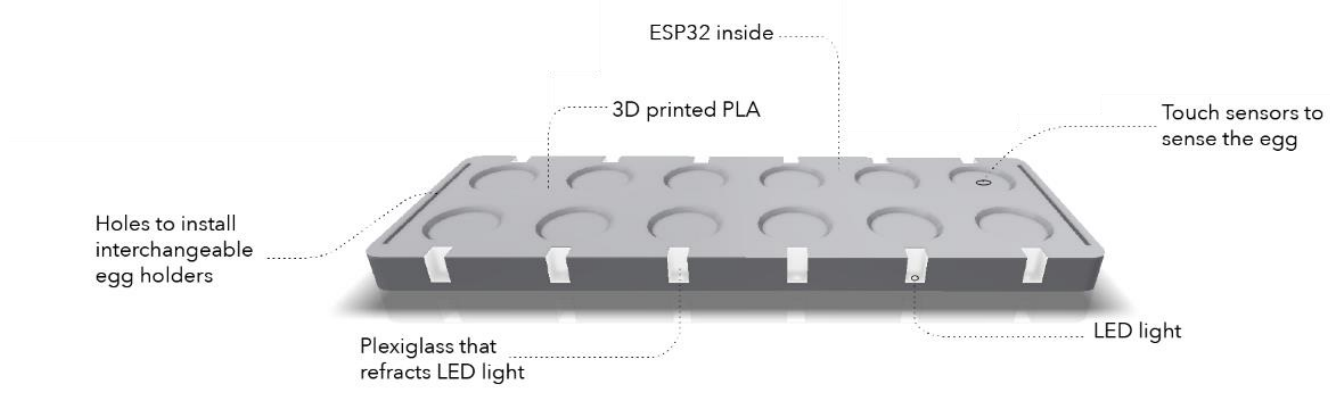

Figure 3. The Smart Egg Tray 3D model

An important unit is the LED light, which is placed close to the bottom of each egg spot, to light it up directly. Each LED is made visible though the tray surface by a Plexiglass layer that refracts the light, giving a blurred appearance yet maintaining the light visibility. One of the most important features of the Smart Tray regards the presence of touch sensors installed under the eggs spots, and used to control each egg independently. The position of the touch sensors is studied so as to recognise the eggs even if they are placed inside the carton. This allows us to place any type of eggs cartons on the Tray, independently of their dimension and size: medium, large and extra-large cartons, respectively containing six, ten or twelve eggs. The Smart Tray can be customised according to the users' preferences, by selecting a specific eggs holder, which can be installed onto the Smart Tray by means of dedicated holes. Many different solutions and shapes have been explored to make the accessories perfectly adaptable to any customer's need (Figure 4).

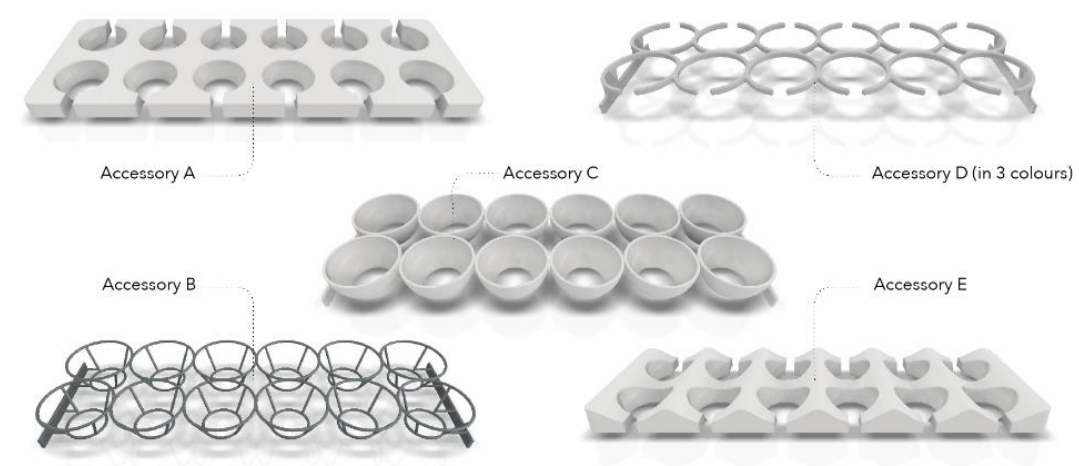

Figure 4. 3D models of the Tray accessories

- Accessory A aims to create the perception of a unique shape with the tray. An open space is present between eggs in order to make each LED visible.

- Accessory B is made by a thin wire shape and allows holding each egg without hiding it.

- Accessory $\mathrm{C}$ presents some cup shapes that are very classic and functional in order to well contain and hold each egg. 
- Accessory D presents rounded shapes, and every circle is cut to let the light pass through it.

- Accessory $\mathrm{E}$ is inspired by waves and gives the illusion that the shape protects and holds the eggs as they are part of it. The lights enhance the value of each egg through the open cuts.

\subsection{Smartphone Applications}

The design of the Parent and Children's applications started by considering the brand identity created for the Smart Egg Tray product, including the design of a specific logo. The design system used is shown in Figure 5, and includes colours, fonts and icons.
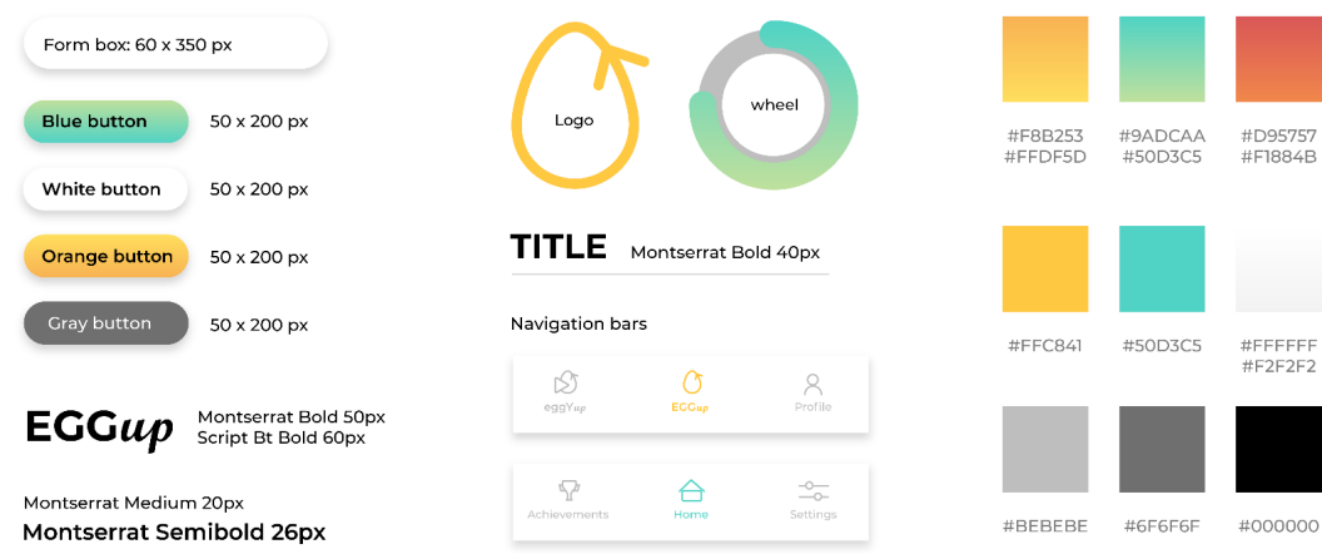

Figure 5. Applications design system

The Parent's application is divided in three main areas, as shown in Figure 6:

- The Profile area, to access the personal account, see the statistics, manage the notifications and receive support in any needed situation.

- The MyEggs area, to check the eggs lifetime. Indeed, the status of the eggs is clearly associated with a colour, and the user can understand at a glance which one is edible, which one is close to the expiration date or already expired.

- An area connecting with the children's application. Here, it is possible to check children's statistics, set goals for the Finding eggs game, etc.

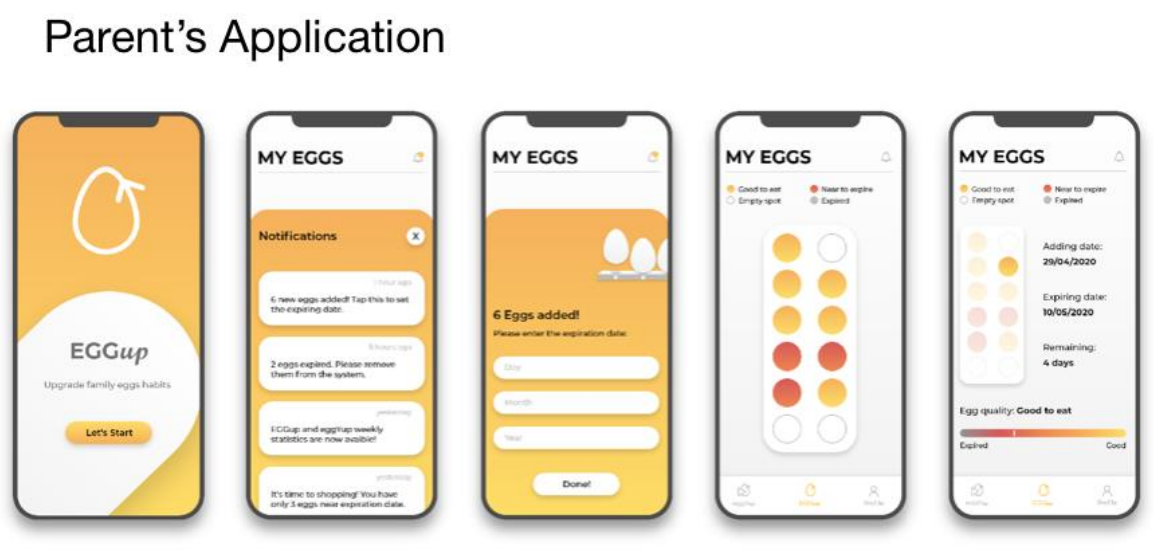

Figure 6. Main areas of parent's application

Similarly, the Children's application presents four main areas, as shown in Figure 7:

- Home, in which it is always possible to check the points score and decide to gain extra points executing some proposed activities.

- Achievements area, which provides full vision of the completed and locked game levels. The levels are divided in rows, providing different games complexity.

- The Check Eggs memory game, in which the children are asked to check eggs present on the Smart Egg Tray inside the fridge and associate each one of them with the correct colour code proposed by the application. In this way, the children can help monitoring the eggs status.

- The Finding eggs game, based on the Augmented Reality Easter Eggs search, where children have to find eggs that are placed and hidden throughout the house (see Figure 8). 


\section{Children's Application}
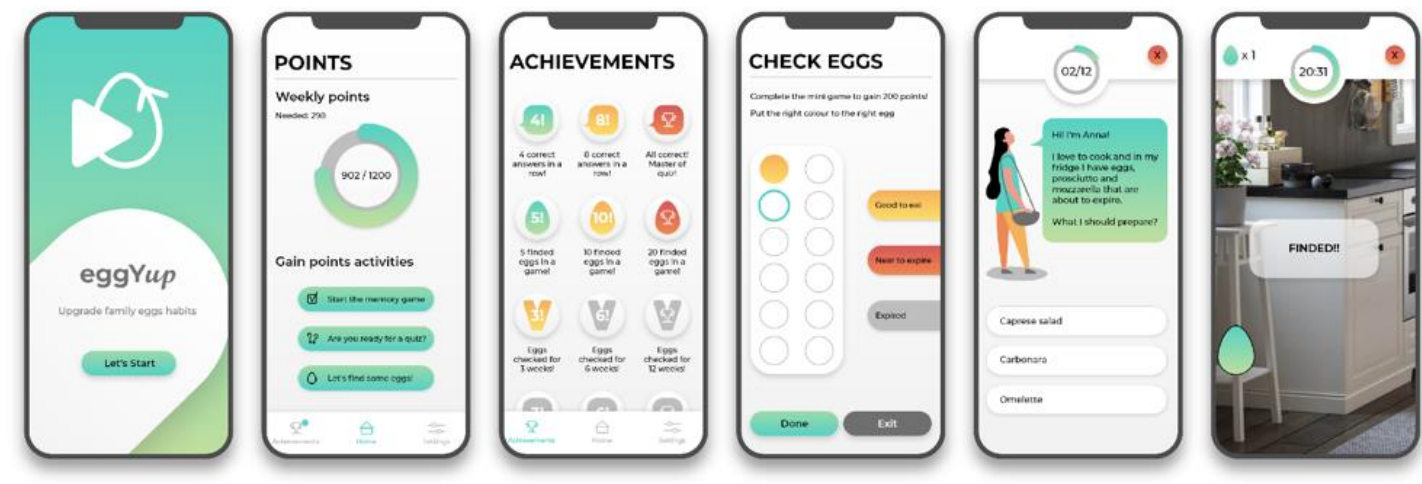

Figure 7. Main areas of children's application
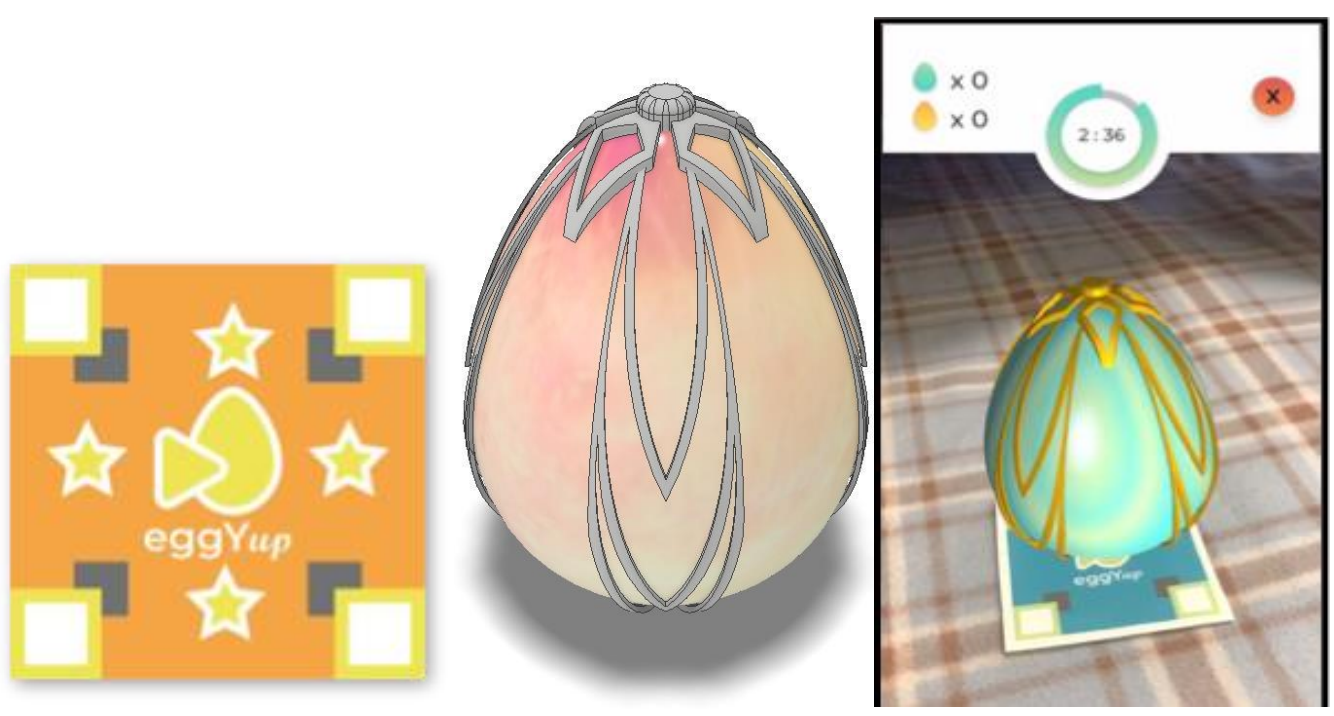

Figure 8. A marker, a 3D model and a screenshot of the Augmented Reality Finding Eggs game

\section{CONCLUSIONS}

The paper described a system, made of a physical product and an interactive application, developed to support users towards a more conscious food consumption in their daily life, as well as to generate awareness about the food waste problem.

Specifically, the EGGup interactive system has been designed and developed with the aim of improving the user's engagement and understanding of the ecological problem and how he/she can act to reduce food waste. Particular attention has been devoted to the design of the application for children. In fact, the authors aimed at developing an interactive and stimulating experience for children transmitting educational content through an entertainment game.

Proper tests on the educational value of the system as well as on parents and children's evaluation of its use and pleasantness have not been performed yet. However, the authors have collected some preliminary comments and opinions from some users (mainly students) that have tried the system. They reported a very high level of appreciation of the system and a high level of pleasantness in using it. Specifically, they stated that the addressed topic is very close to their personal interests and environmental awareness. Nonetheless, they were not aware of much of the information heard during the interactive experience and are satisfied with what they have learned. Regarding the AR Finding eggs game, they found it technically very stable and the digital contents of great entertainment and stimulating to continue using the application. It is worth mentioning that these initial evaluations will certainly need to be properly addressed in the near future. 
However, in an envisaged scenario, interactive systems similar to that one presented can be developed and implemented for a wide range of educational purposes concerning ecological, scientific and technological topics, and can be used to support users towards more sustainable behaviours.

Moreover, similar systems can be developed to accommodate different types of fresh food products, for example fruits and vegetables. Indeed, this idea can be adapted to design a food storage system placed outside of the fridge and connected to an electric plug, with the aim of persuading people to a conscious food consumption.

\section{REFERENCES}

Bhamra, T., Lilley, D., Tang, T. (2011), "Design for Sustainable Behaviour: Using Products to Change Consumer Behaviour", Design Journal, 14(4), pp. 427-445

Bhamra, T., Lofthouse, V. (2007), "Design for sustainability: a practical approach", Gower Publishing

Buzby, J.C., Hodan, F.W., Hyman, J. (2014), "The Estimated Amount, Value, and Calories of Postharvest Food Losses at the Retail and Consumer Levels in the United States", U.S. Department of Agriculture, Economic Research Service

Ceschin, F., Gaziulusoy, I. (2016), "Evolution of design for sustainability: From product design to design for system innovations and transitions", Design Studies, Vol. 47, pp. 118-163

Graziosi, S., Ferrise, F., Costanzi, A., Bordegoni, M. (2015), "The Use Of Multisensory Feedback To Make Users Behave In A Sustainable Way", International Conference On Engineering Design, ICED15, Milano, Italy, 27-30 July 2015

https://climate.nasa.gov/images-of-change

https://secondverse.org/\#/after-ice/

https://www.wikitude.com/wikitude-eovision-bring-augmented-reality-frankfurt-book-fair/

Montazeri, S., Panos, P., Rich, G. (2015), "Design For Behavior Change: An Elaboration-Based Approach To Persuasion In Product Design”, International Conference On Engineering Design, ICED15, Milano, Italy, 27-30 July 2015

Pecher, D., Zwaan, R.A. (2005), "Grounding Cognition: The Role of Perception and Action in Memory, Language, and Thinking", Cambridge University Press.

Prochaska, J.O.; DiClemente, C.C. (1983), "Stages and processes of self-change of smoking: toward an integrative model of change". Journal of consulting and clinical psychology, 51(3), pp. 390-395

Scurati, G.W., Carulli, M., Ferrise, F., Bordegoni, M. (2020), "Sustainable behaviour: A framework for the design of products for behaviour change", Emotional Engineering, Vol. 8: Emotion in the Emerging World, pp. $65-83$

Selvefors, A., Strömberg, H., Renström, S. (2016), "What a designer can change: a proposal for a categorisation of artefact-related aspects", DRS2016 Conference.

Tang, T., Bhamra, T.A., (2008), "Changing energy consumption behaviour through sustainable product design". IN: Marjanovic, D. ... et al, (eds.). DS 48: Proceedings of DESIGN 2008, the 10th International Design Conference, Dubrovnik, Croatia, 19-22 May 2008, pp. 1359-1366

Wahlen, S., Winkel, T. (2016), "Reference Module in Food Science - Household Food Waste"

Wever, R., van Kuijk, J., Boks, C. (2008), "User-centred design for sustainable behaviour”, International Journal of Sustainable Engineering, Vol. 1, pp. 9-20

World Commission on Environment and Development (1987), "Our Common Future", Oxford, New York: Oxford University Press 